\title{
Long Noncoding RNAs of the Arterial Wall as Therapeutic Agents and Targets in Atherosclerosis
}

\author{
Lesca M. Holdt ${ }^{1}$ Alexander Kohlmaier ${ }^{1} \quad$ Daniel Teupser $^{1}$ \\ ${ }^{1}$ Institute of Laboratory Medicine, University Hospital, LMU Munich, \\ Munich, Germany \\ Thromb Haemost 2019;119:1222-1236. \\ Address for correspondence Daniel Teupser, MD, PhD, Institute of \\ Laboratory Medicine, University Hospital, LMU Munich, \\ Marchioninistr. 15, 81377 Munich, Germany \\ (e-mail: daniel.teupser@med.uni-muenchen.de).
}

\begin{abstract}
Long noncoding ribonucleic acids (IncRNAs) have been defined as transcripts which are $>200$ ribonucleotides in size and are not translated into protein. Recent work has shown that many IncRNAs do have specific molecular functions and biological effects, and are involved in a growing number of diseases, including atherosclerosis. As a consequence, IncRNAs are also becoming interesting targets for therapeutic intervention. Here, we focus on IncRNAs which are expressed in the arterial wall, and describe potential RNA therapeutic approaches of atherosclerosis by manipulating IncRNAs without affecting genome deoxyribonucleic acid content: Starting out with an over-

Keywords

- transcription

- splicing

- IncRNAs

- circRNAs

- gene expression view of all IncRNAs that have so far been implicated in atherosclerosis by in vivo studies, we describe methodologies for their activation, inactivation, and RNA sequence manipulation. We continue by addressing how artificial (nonnative) therapeutic IncRNAs may be designed, and which molecular functions these designer IncRNAs may exploit. We conclude with an outlook on approaches for chemical IncRNA modification, RNA mass production, and site-specific therapeutic delivery.
\end{abstract}

\section{Introduction}

It is well known today that a large portion of the human genome $(\sim 70 \%)$ is transcribed and that the majority of the produced transcripts are noncoding (ENCODE or FANTOM consortia). ${ }^{1-4}$ Among the 200,000 known transcripts, around 28,000 stem from long noncoding ribonucleic acid (lncRNA) loci (GENCODE). ${ }^{5}$ Genome-wide association studies (GWAS) recurrently find disease-linked genetic variation in the nonprotein-coding sequence space, ${ }^{6}$ often overlapping gene regulatory elements like enhancers, which are actively transcribed and give rise to noncoding RNAs. ${ }^{7,8}$ Concurrently, transcriptomic analyses in patient cohorts reveal numerous IncRNAs which are differentially expressed in diseased tissues. Recent work has shown that many lncRNAs are functional, leading to the notion that lncRNAs may represent a large class of potential therapeutic agents and targets. In this minireview, we describe lncRNAs linked to atherosclerosis in humans which are expressed in cells of the arterial wall (wall endothelial cells [ECs], vascular smooth muscle cells
[VSMCs], and circulating and resident immune cells). We do not cover the roles of IncRNAs regulating atherosclerosis risk factors, such as lipid metabolism, diabetes, or hypertension, or adaptation to ischemic stress. We describe molecular roles of relevant disease-linked lncRNAs, and techniques to therapeutically manipulate them at the RNA level, referred to as RNA therapeutics, an approach that focuses on controlling RNA form and sequence without affecting the deoxyribonucleic acid (DNA) in our genomes.

\section{LncRNA Classes and their Suggested Therapeutic Potential}

IncRNAs come in two major flavors, with tens of thousands of cases in each class: (1) linear IncRNAs from dedicated lncRNA genes with their own promoter and terminator and (2) covalently closed circular IncRNAs. The latter are produced through splicing from existing primary transcripts of any type of gene (-Fig. 1A, - Table 1) (see Refs. ${ }^{9}$ and ${ }^{10}$ for review). Linear and circular IncRNA production and received

November 15, 2018

accepted after revision

April 23, 2019
DOI https://doi.org/

$10.1055 / \mathrm{s}-0039-1692680$.

ISSN 0340-6245. (c) 2019 Georg Thieme Verlag KG
Stuttgart · New York
License terms

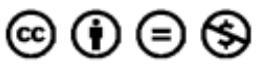



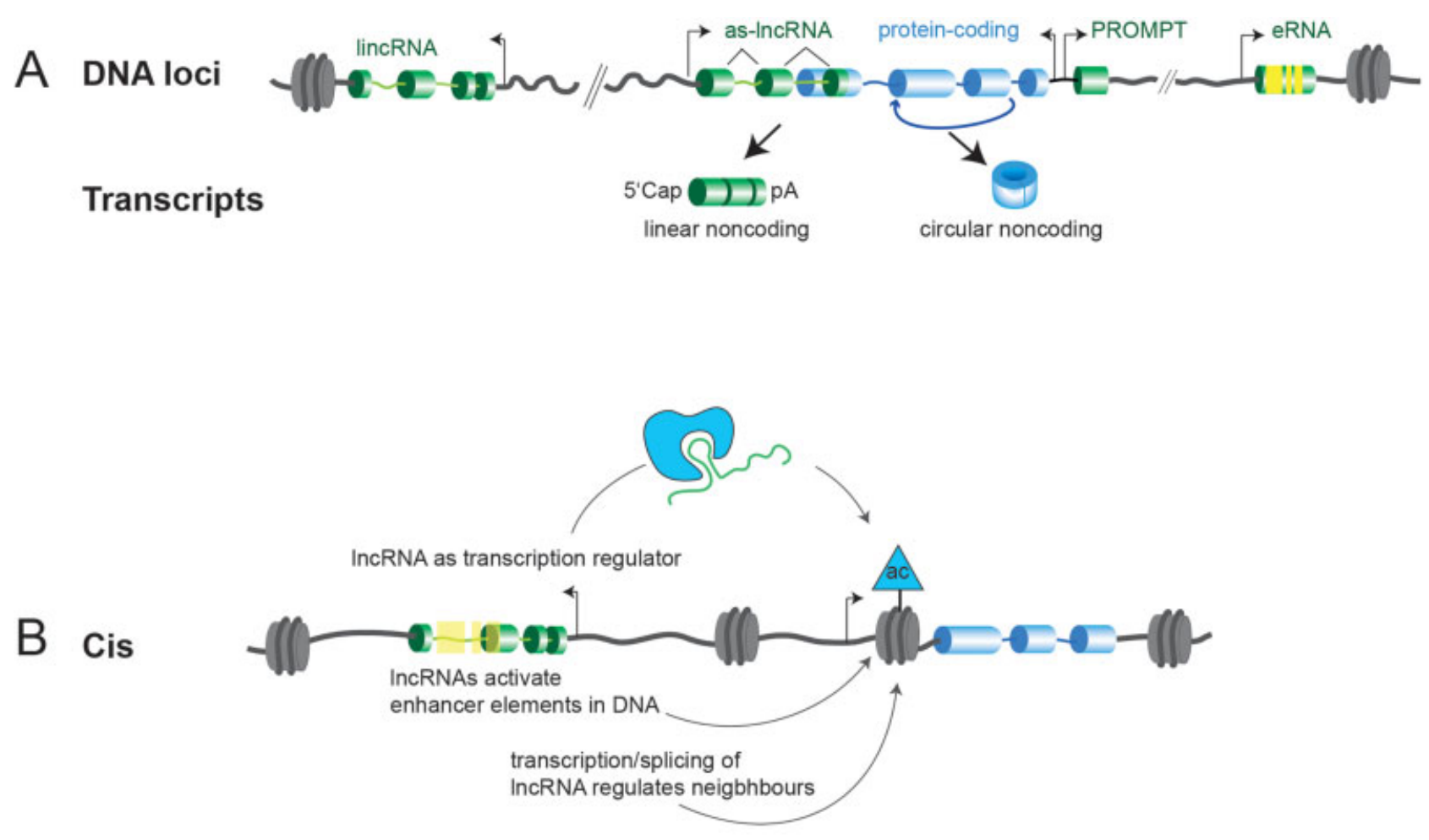

Trans

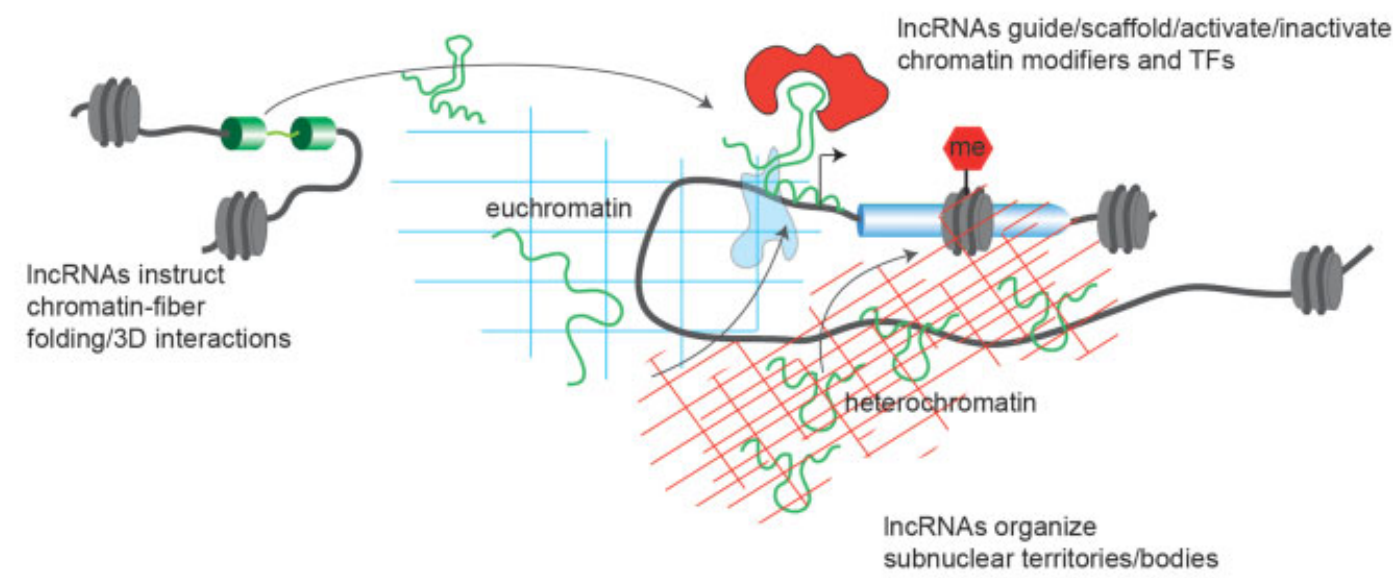

Others

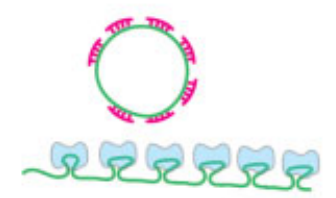

IncRNA as sponges or decoys for microRNAs / proteins

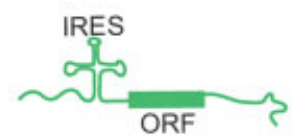

translation of small polypeptides from IncRNAs

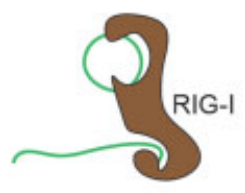

stimulation of innate immune signalling by uncapped or circular RNA

Fig. 1 Classes and functions of long noncoding ribonucleic acids (IncRNAs). (A) The positioning of IncRNA genes relative to protein-coding genes is a classification criterion. (1) Large intergenic noncoding RNAs (lincRNAs). (2) Natural antisense transcripts (as-IncRNAs). (3) Promoter upstream antisense transcripts (PROMPTs). (4) Enhancer RNAs (eRNAs). IncRNAs transcripts can be linear or circular. Circular IncRNAs are produced by backsplicing of a downstream exon to an upstream exon and do not carry 5'Cap or 3'polyA tail. (B) Functions of IncRNA with atherosclerotic relevance. Functions can be classified in cis- and trans-acting roles in transcriptional regulation in the nucleus, and in standalone effects (others) in the cytoplasm (bottom). During transcription control, either the IncRNA transcript is functional, or the progression of the RNA polymerase over the IncRNA gene body is the functional determinant (coinciding with chromatin-decompaction of deoxyribonucleic acid [DNA] elements at the IncRNA locus, or with splicing of nascent IncRNA still attached to its DNA template). Abbreviations: IRES, internal ribosome entry site; ORF, open reading frame; RIG-I, retinoic acid inducible gene I; TF, transcription factor. 
Table 1 Dichotomy of linear and circular long noncoding RNAs

\begin{tabular}{|l|l|}
\hline Linear IncRNAs & circRNAs (3'-5'-linked exon-containing circular RNAs) \\
\hline$>200$ nucleotides (nts) in length \\
\hline Non-protein-coding (lacking open reading frames $>100$ codons) \\
\hline Tens of thousands of cases \\
\hline Many isoforms per case \\
\hline Produced with cell type- and context-specificity \\
\hline Mostly lower abundance per cell than average mRNAs \\
\hline Considered to be mostly functional & Average length $\sim 550$ nts \\
\hline Average length $\sim 1,000$ nts & Cytoplasmic enrichment (not all) \\
\hline Nuclear enrichment (not all) & $\begin{array}{l}\text { Generically lacking 5'Cap and 3' polyA tails due to covalent 3'-5' } \\
\text { backbone linkage after backsplicing }\end{array}$ \\
\hline $\begin{array}{l}\text { Mostly carrying 5'Cap and 3' polyA tails } \\
\text { (depending on IncRNA class) }\end{array}$ & Produced by spliceosome from primary transcripts (mRNAs or IncRNAs) \\
\hline $\begin{array}{l}\text { Produced by transcription from unique } \\
\text { transcriptional units with their own promoter }\end{array}$
\end{tabular}

Abbreviation: IncRNA, long noncoding ribonucleic acid.

abundance are regulated and are cell-type specific. Both linear and circular IncRNAs have been shown to be overall functional in one pathway or another. IncRNAs effector mechanisms are diverse and complex (-Fig. 1B), making it nontrivial to decide which one to interfere with for therapy:

(1) IncRNAs guide, scaffold, and control transcriptionregulating protein complexes:

Many lncRNAs are known to affect transcription of RNAP I and II target genes, often by impacting chromatin readers and writers in gene promoter control. ${ }^{11}$ Examples with relevance for atherosclerosis are ANRIL, H19, lincRNA-p21, MALAT1, MEG3, NEAT1, or TUG1 (-Table 2). IncRNAs affect transcription in cis, or also in trans, especially if their steadystate abundance is large and allows diffusion of the lncRNA throughout the nucleoplasm. Mechanistically, lncRNAs can recruit chromatin remodelers to target genes via hybridization to DNA, or control their enzymatic activity, or function as negative decoys. IncRNAs can also regulate the transcription of microRNA and other noncoding RNAs (a process distinct from RNA sponging, see 5).

(2) Enhancer RNAs/eRNAs:

Active enhancers for gene promoters have recently been found to be transcribed and to give rise to enhancer lncRNAs (eRNAs). These can confer enhancer activity by capturing the promoter-contacting Mediator protein complex. ${ }^{12}$ Examples of eRNAs important for atherosclerosis are HOTTIP, LEENE, and SMILR (-Table 2). Depending on enhancer, both, the eRNA and the chromatin-opening during transcription of the eRNA locus can be therapeutically relevant. ${ }^{11}$

(3) Antisense lncRNAs/asRNAs:

Some lncRNA genes reside within protein-coding gene units, even overlapping coding exons in antisense. Effects on host genes can be positive and negative. Examples with relevance for atherosclerosis are ANRIL, HOXC-AS1, MALAT1, and SENCR (-Table 2). Globally, antisense transcription dampens transcriptional noise and is not part of signaldependent expression control. ${ }^{13}$ Therapeutic programming through asRNAs is complex, because it may require engineering the genomic locus.

\section{(4) LncRNAs in subnuclear bodies:}

Some lncRNAs can affect other genes through their architectural role in assembling eu- and heterochromatin subnuclear territories. Examples are MALAT1 in Polycomb bodies, ${ }^{14}$ or NEAT1 in paraspeckles. ${ }^{15}$ These indirectly affect gene expression and pre-messenger RNA (mRNA) processing, respectively, depending on the vicinity of genes to these subnuclear bodies. The broadness of the effect and the complexity of the process make it difficult to achieve specificity in therapy.

\section{(5) IncRNAs as microRNA sponge:}

Although many publications implicate endogenous lncRNAs as microRNA sponges (and as inhibitors of microRNA availability and function, therein), many of these reports are met with criticism because evidence often bases on uncontrolled IncRNA overexpression. Few IncRNAs pass the stoichiometric requirements for sponging, though, as most are endogenously not sufficiently highly expressed compared with the number of corresponding microRNA targets and copy numbers of microRNAs per cell (see Ref. ${ }^{16}$ for overview).

(6) IncRNAs which bind and regulate proteins:

Mass spectrometric analyses showed that a single lncRNA can bind dozens of different proteins in the nucleus and in the cytoplasm, and thereby affect multiple molecular mechanisms at once ${ }^{17}$ : This concept is best seen for wellstudied lncRNAs like XIST, which was found to bind $>80$ proteins, indicating that it participated in DNA and histone modification and RNA remodeling machineries. ${ }^{17}$ With relevance to atherosclerosis, circular ANRIL (circANRIL) binds to the rRNA processing PeBoW complex for protein translation 
control, ${ }^{18}$ whereas linear ANRIL interacts with members of the PRC $1^{19}$ as well as with the PRC2 Polycomb-repressive complexes ${ }^{19-21}$ during presumptive transcription control of target genes (-Table 2). In another case, TUG1 can serve as competing endogenous RNA, and also promote gene activity by chromatin fiber positioning, ${ }^{14}$ and was even suggested to regulate cytoskeletal contractility by enhancing the cytoplasmic activity of Ezh2 toward methylating $\alpha$-actin ${ }^{22,23}$ (-Table 2). Conceptually, a IncRNA may also hierarchically regulate a single transcriptional regulator, thereby influencing, in one step, a range of downstream genes and cellular processes. For example, $N R O N$ participates in scaffolding and restraining the nuclear factor of activated T cell (NFAT) transcription factor in a latently active form in the cytoplasm in unstimulated resting $\mathrm{T}$ cells. ${ }^{24,25}$ Transcription factor control is recurrently ascribed to many IncRNAs (-Table 2). Together, there is potential for lncRNAs in tuning protein complex activity as "RNA-drugs," akin to smallmolecule drugs, but lncRNA-dependent activity changes in IncRNA:protein complexes are difficult to study, and so far not understood in any case in mechanistic and structural detail.

\section{(7) Protein translation from noncoding RNA:}

Despite being nonprotein-coding by definition, some IncRNAs do contain small open reading frames (sORFs), some of which can be translated. Atherosclerosis-specific functions of sORFs are so far unknown. Still, protein expression is, in principle, possible from, both, linear and circular IncRNAs, if the required translation-initiating signals are artificially incorporated into synthetic constructs ${ }^{26}$ (see chapter on "Disease Therapy by Artificial (Nonnative) Designer lncRNAs" below).

\section{(8) Bifunctional noncoding mRNAs:}

The clear separation between coding and noncoding RNA is blurring and some mRNAs carry functions also as untranslated RNAs. For example, the steroid receptor RNA, which is in principle protein-coding, also functions as IncRNA-in chromatin regulation at specific target genes in the nucleus. ${ }^{27,28}$ And p53, as noncoding RNA, binds and affects the activity of the MDM2 enzyme through structural RNA motifs. ${ }^{29}$ In another more indirect case, under stress cohorts of several hundred mRNAs become transcribed from alternative upstream transcription start sites, a process that blocks their transcription from the actual promoters. This shift leads to a novel longer RNA isoforms that include a short upstream ORFs with a new stop codon, whose translation blocks the translation of the actual functional protein encoded in a given locus. ${ }^{30}$ Thereby, functionality lies less in an active role as cis/trans-acting noncoding RNA, but more in indirect effects of translation control on the proteome. ${ }^{31,32}$ These findings expand the operational space for noncoding RNA therapeutics ( - Table $\mathbf{1}$ ).

\section{Known Roles of IncRNAs in Atherosclerosis}

Limiting our review to those IncRNAs expressed in the vascular wall and functioning in atherosclerosis, 31 lncRNAs have so far been implicated in vascular cell types (-Table 2 ). Most were initially found because of being differentially expressed in patient cohorts. Only a few (ANRIL, circANRIL, MIAT, H19, LINC00305), were identified by unbiased GWAS. Fifteen of the listed IncRNAs were studied in immune cell types (such as peripheral blood monocytes, circulating and vascular wall macrophages, or foam cells), 17 in ECs, and 13 in VSMCs.

In the following, we highlight lncRNAs from - Table 2 where in vivo evidence for therapeutic potential exists. Four groups may be distinguished: (1) IncRNAs with a documented therapeutic benefit for atherosclerosis, (2) IncRNAs with a benefit for other vascular diseases, (3) IncRNAs essential for normal vascular biology, and (4) IncRNAs generally involved in inflammatory signaling (with expected relevance for atherosclerosis).

1. In vivo evidence for therapeutic a potential in atherosclerosis has been determined only for one IncRNA: Neat1, a wellknown IncRNA, ${ }^{76}$ is upregulated in plaques, and knockingout Neat1 in mice decreased neointimal lesions in an atherosclerosis model. ${ }^{64}$ Since a full-body mouse knockout was analyzed, it remained unclear in which cell type Neat1 functioned. ${ }^{64} \mathrm{~A}$ function in VSMCs was tested in vitro: During carotid artery injury, VSMCs usually dedifferentiate from a quiescent to a proliferative/synthetic phenotype, and Neat 1 promoted this atherogenic switch by repressing the function of the chromatin activator WDR5/MLL on serum response factor (SRF) target genes. ${ }^{64}$ Consequently, therapeutically reducing NEAT1 in VSMCs in lesions might be useful for antagonizing the proatherogenic myocardinSRF-dependent phenotypic switching of VSMCs, ${ }^{64,77}$ or the proatherogenic oxidized low-density lipoprotein (ox-LDL)dependent inflammatory signaling in macrophages. ${ }^{78}$ However, given that VSMC proliferation and matrix synthesis are in other contexts also considered beneficial (for example, for plaque repair or for fibrous cap stability) (see Ref. ${ }^{79}$ for review), more work is needed before NEAT1 can be considered for cell-type-specific therapy.

2. Three IncRNAs showed therapeutic potential at least regarding other vascular diseases: Downregulation of $\mathrm{H} 19$ ameliorates aneurysms, ${ }^{38}$ and downregulation of Miat, ${ }^{62}$ circHipk $3,{ }^{33}$ or $C Z N F 609^{34}$ ameliorates diabetic retinopathy.

3. Two IncRNAs, MeXis ${ }^{61}$ and Malat1, ${ }^{57,80,81}$ have been studied by knockouts in mice. Nevertheless, the therapeutic potential of these IncRNAs remains untested: In the first case, MeXis levels were found to increase by ox-LDL stimulation of macrophages, upon which this IncRNA induced the Abca1 transporter and cholesterol efflux. ${ }^{61}$ Since knockout of MeXis led to increased plaque growth in bone marrow reconstitution experiments of $\mathrm{ldlr}^{-/-}$mice, therapeutically increasing MeXis (human TCONS00016111) expression, especially in patients with single-nucleotide polymorphisms (SNPs) in this gene, ${ }^{61}$ might potentially be therapeutically relevant. Care is advised, however, when interpreting data for Malat1, which has opposing roles in different cardiovascular conditions: On the one hand, MALAT1 was found to be downregulated in the plaque, ${ }^{55}$ and knocking- 


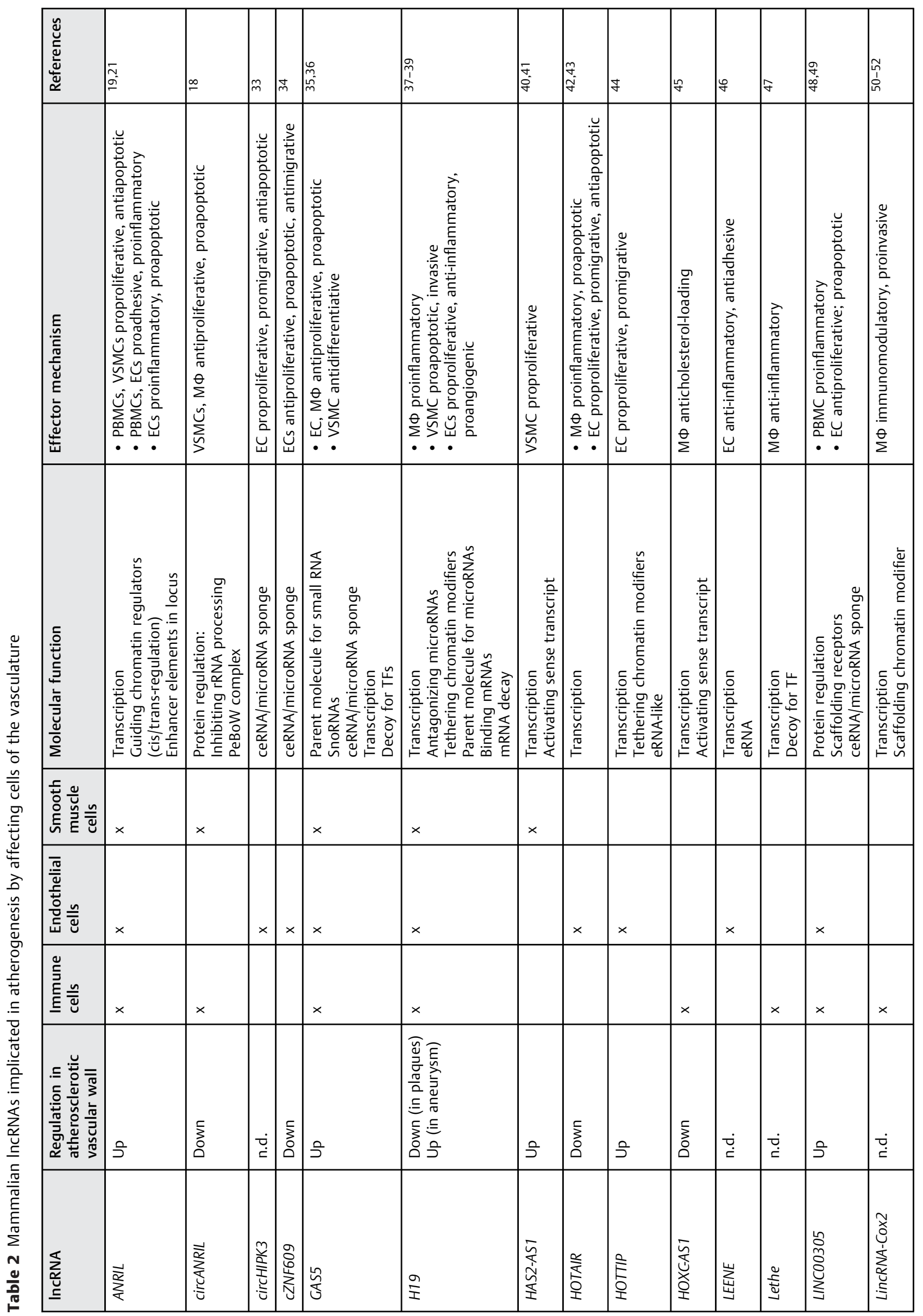




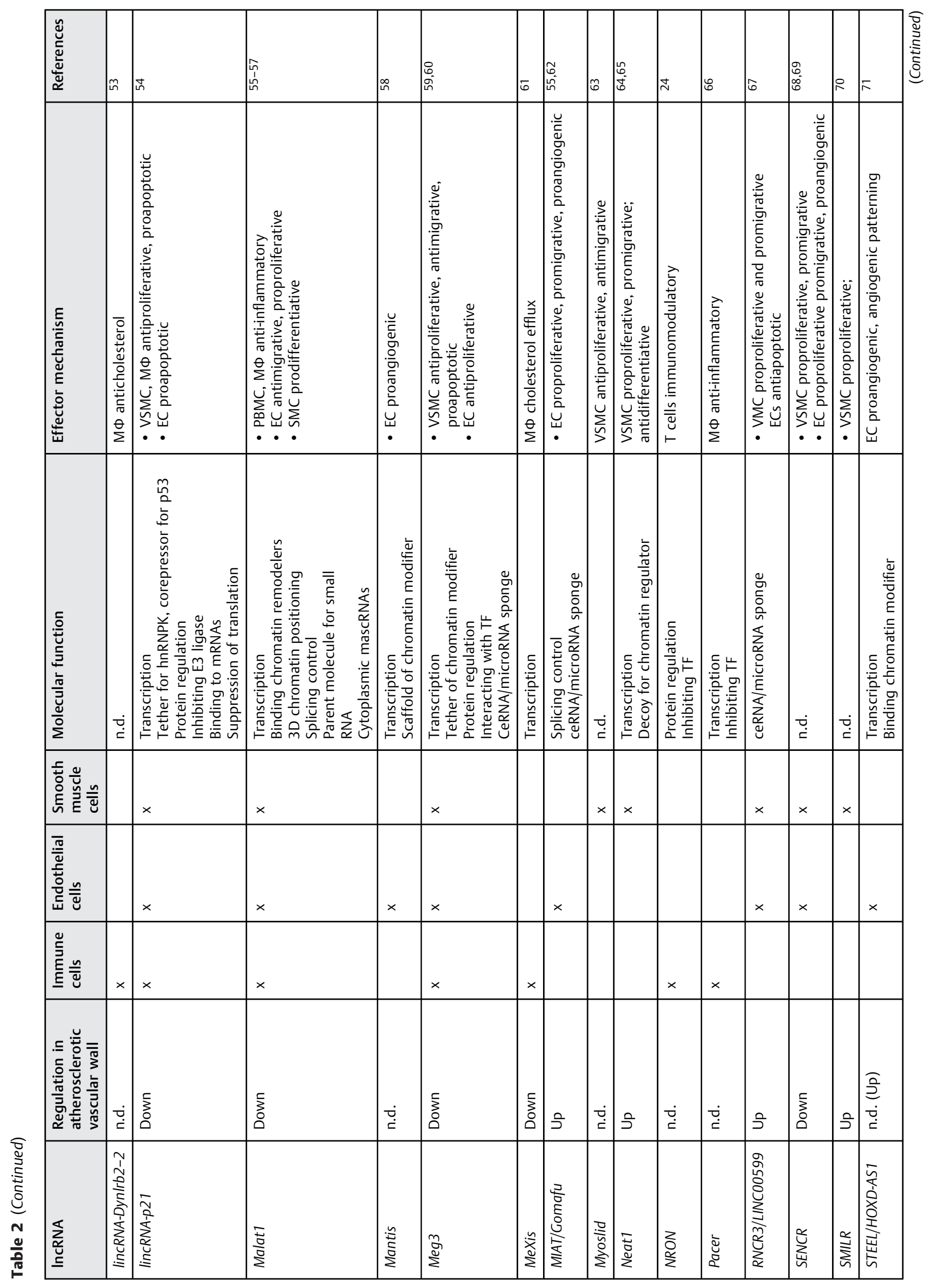




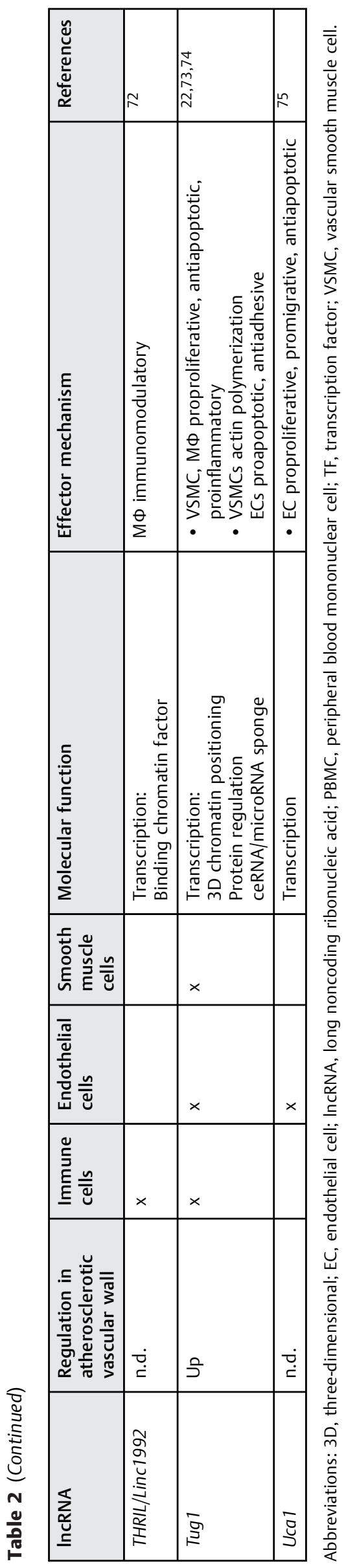

out Malat1 in mice was recently found to trigger immune dysregulation and atherosclerosis in an apoe ${ }^{-/-}$mutant background, remarkably even without the challenge by a coronary artery disease-triggering fat-rich diet. ${ }^{81}$ With a similar direction of effect, Malat1 knockouts developed larger infarcts in brain ischemic mouse models. ${ }^{82,83}$ These two studies suggested that it might be worthwhile to normalize MALAT1 through overexpression during therapy. Yet, in other contexts, such as aortic thoracic aneurysms or vascular diseases of the Marfan syndrome, beneficial effects seemed to lie rather in MALAT1 inhibition, and not in its induction. ${ }^{57}$ Also, bluntly overexpressing Malat 1 may have limitations because it is known from other studies that increases in MALAT1 would promote cancer by effects on cell migration, metastasis, and angiogenesis in hypoxic conditions. $^{84,85}$ Summarizing, different studies showed context- and cell type-dependent therapeutic requirements for MALAT1. Consequently, further studies and tools for achieving tissue tropism in delivering therapeutic IncRNA only to specific cells, or for conditional activation/ inactivation of lncRNAs in specific conditions and cells, will be required.

4. Twelve IncRNAs have been indirectly implicated in atherogenesis through in vitro studies in cultured vascular cell types, or through in vivo insight in their effectors. A major group in this class comprises 6 IncRNAs involved in modulating inflammatory signaling in vivo (lincRNACox2, PACER, Lethe, THRIL, NRON, STEEL) (-Table 2). These have considerable therapeutic potential because of the intimate contribution of inflammation to atherogenesis (see following chapter on "Disease Therapy by Manipulating Endogenous IncRNAs".). The rest of IncRNAs in this group control ECs (Miat), VSMCs (Myoslid), or both (Gas5, lincRNA-p21, Meg3), through functioning in diverse processes.

\section{Translating Molecular Function to Therapeutic Value}

In the following, we summarize key therapeutic principles centered on IncRNAs (-Fig. 2A). Thereby, we distinguish (1) therapeutic approaches exploiting endogenous IncRNA functionality, and (2) approaches based on artificial (nonnative) designer lncRNAs.

\section{Disease Therapy by Manipulating Endogenous IncRNAs}

During the onset of disease, lncRNAs expression levels change in cell- and context-dependent modes. For therapy, IncRNAs that are overactive in disease can be normalized by knockdown approaches. Gain-of-function approaches or RNA sequence correction can be used to antagonize disease-linked changes at the RNA level in other lncRNAs.

(1) Transcriptional control is, so far, the major known function of noncoding RNAs. Twenty-one of 31 atherosclerosis-linked lncRNAs function as guides, scaffolds, and regulators of chromatin factors (- Table 2). In contrast to 
A

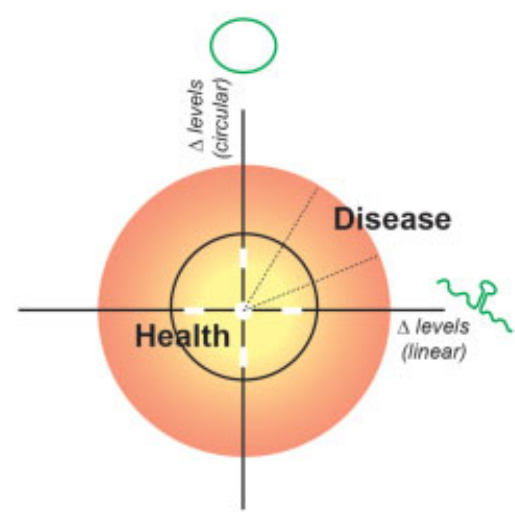

\section{Environmental stimuli}

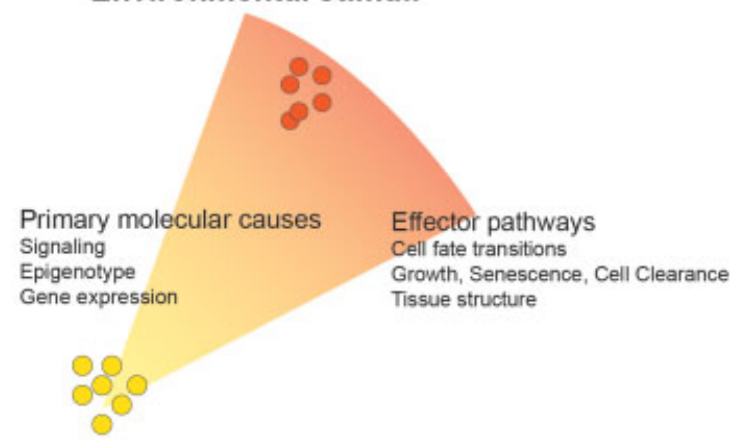

Genetic predisposition

\section{B}

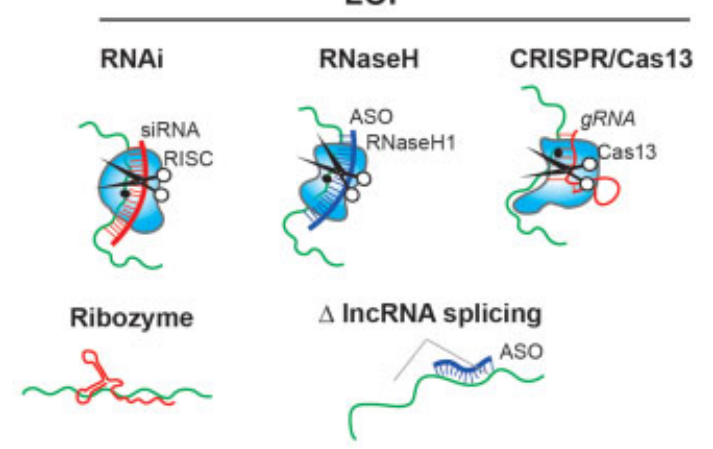

GOF

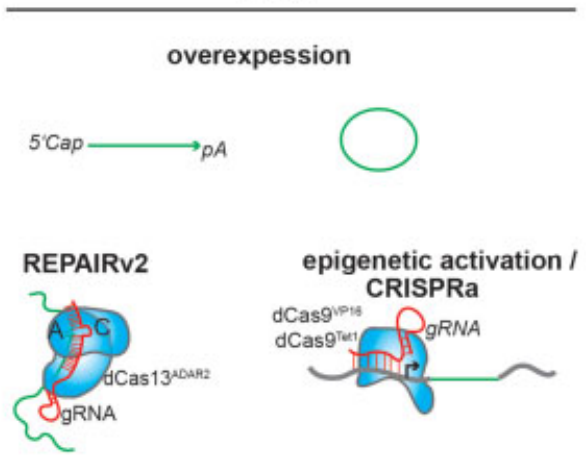

Fig. 2 Concepts and tools for using long noncoding ribonucleic acids (IncRNAs) of the arterial wall in antiatherogenic therapy. (A) Concepts for IncRNA therapy. IncRNA genotype and the ratio of linear and circular IncRNA transcripts must be considered during therapy (left panel). IncRNAs can be therapeutically used to correct the primary molecular causes of disease or to block the pathologically induced cellular effector pathways that confer plaque growth (right panel). Another option would be to, more generally, kill-off disease-causing cells in plaques (right panel). The healthy cell state is denoted in yellow, the diseased state in red. (B) Tools for manipulating IncRNA levels in cells, classified under LOF (loss-offunction) and GOF (gain-of-function) approaches. Target RNAs are labeled in green. Targeting RNAs or ribozymes are marked in red, targeting deoxyribonucleic acid (DNA)-like antisense oligonucleotides (ASOs) in blue. Scissors denote target RNA cleavage by nucleases. Abbreviations: CRISPRa, CRISPR activation for promoter activation; $\mathrm{dCas} 9^{\mathrm{VP} 16}$, inactive Cas9 fused to the generic herpes simplex viral protein 16 (VP16) activation domain; dCas $9^{\mathrm{Tet} 1}$, inactive Cas9 fusion with catalytic domain of Tet1 (DNA 5-methylcytosine demethylase); dCas13 ${ }^{A D A R 2}$, catalytically inactive Cas 13 RNA-guided RNase fused to the ADAR2 (adenosine deaminases acting on RNA 2); gRNA, CRISPR guide RNA; PA - poly (A) tail; REPAIR, RNA Editing for Programmable A to I Replacement; RNAi, RNA interference.

small-molecule drugs which inhibit broadly-acting chromatin factors (such as DNA/histone methyltransferases, demethylases, acetylases, and chromatin readers), ${ }^{86}$ epigenetic therapy through manipulating lncRNA levels and sequence may have the advantage that it allows, in principle, to sequence-specifically control specific subsets of target genes. Separately, it becomes a therapeutic option to guide generic repressor proteins (KRAB- and Chromo-domains) or activators (VP16) to promoters of disease-linked genes via noncoding RNAs. ${ }^{87,88}$

(2) Controlling splicing is equally important for therapy as transcription control. Splice-regulating antisense oligonucleotides (ASOs) can be used to tune splicing in mRNAs and IncRNAs. Additionally, a new therapeutic front was opened when it was found that cotranscriptional circRNA biogenesis interfered with linear RNA biogenesis. ${ }^{89-91} \mathrm{~A}$ well-studied case is ANRIL, transcribed from Chr9p21 in humans, the most prominent atherosclerosis risk loci known so far. ${ }^{18,92}$ Linear ANRIL levels positively correlate with atherosclerosis severity, while circANRIL levels anticorrelate with atherosclerosis. ${ }^{18,21}$ While linear ANRIL expression causes transitions reminiscent of atherogenesis (inflammation, overproliferation, adhesion in macrophages and VSMCs), ${ }^{19-21,93-95}$ circANRIL mediates opposite effects by blocking proliferation and enhancing cell death rates. ${ }^{18}$ Thus, one way to decrease atherosclerosis risk would be to coincidently decrease linear ANRIL and increase circANRIL, because linear splice forms are known to be increased and circular isoforms decreased in atherosclerosis. How to therapeutically re-engineer the wildtype splicing pattern in a locus is highly complex, as learned from diseases like muscular dystrophies that arise from splicing defects (see Ref. ${ }^{96}$ for a recent review), and it has not yet been practically achieved to simultaneously correct levels of linear and circular ANRIL. Theoretically, and confined to RNA-centric approaches, it would be possible to deliver in vitro produced synthetic circANRIL together with ASOs that target exonic ANRIL sequences 
that are not contained in the circular isoforms. Other options would be to use splice-changing ASOs, that inhibit forward splicing, and promote intron-backfolding for assisting backsplicing and circularization. Finally, deeper insight into how specific atherosclerosis-linked SNPs in ANRIL affect splice site choice ${ }^{92}$ (e.g., through RNA-binding proteins), may allow to get a grip on deliberately affecting circularization.

(3) Proinflammatory signaling drives atherogenesis and various IncRNAs regulate inflammation-dependent gene expression in different cell types. For example, during nuclear factor kappa B signaling in macrophages, LincRNA-Cox2 represses numerous genes by scaffolding RelA-p50 into SWI/SNF complexes. ${ }^{51}$ In contrast, PACER upregulates $C O X-2$, a proatherogenic cyclooxygenase, by interfering with the formation of repressive p50:p50 homodimers, ${ }^{66}$ and Lethe inhibits RelA binding to DNA. ${ }^{47}$ Other IncRNAs are active in T cells or ECs: NRON scaffolds the cytoplasmic IQGAP1/NFAT1 protein complex, thereby restraining calcineurin from activating the proinflammatory NFAT1 transcription factor in T cells. ${ }^{24,97}$ In ECs, STEEL recruits the activating poly-adenosine diphosphate ribosylase PARP1 to KLF2 and eNOS. ${ }^{71}$ Depleting PARP1 is known to limit atherosclerotic plaque growth, ${ }^{98}$ suggesting that inhibiting STEEL could be interesting. Together, upregulating Lethe and downregulating lincRNA-Cox2, PACER, and THRIL may be therapeutically useful (see Refs. ${ }^{99}$ and ${ }^{100}$ for review on atherogenic inflammation).

\section{Disease Therapy by Artificial (Nonnative) Designer IncRNAs}

To achieve IncRNAs with novel functionality, endogenous RNA sequence can be altered, or synthetic constructs are overexpressed. These can contain sequence combinations not existing in endogenous RNA, or stem from in vitro evolution routines:

(1) Although microRNA sponging is not considered a common endogenous function for IncRNAs, therapeutically overexpressed IncRNAs are more abundant than endogenous RNAs and may very well become sponges. Such artificial sponges can be optimized by increasing microRNA-binding sites, and by optimally spacing them. ${ }^{101}$ Furthermore, if target-matched sites are shortened from 8 to $6 \mathrm{nt}$, microRNA degradation happens instead of sponging, opening therapeutic possibilities even further. ${ }^{16}$ circRNAs may become the superior type of sponges because circRNAs are more stable against cellular exoribonucleases than linear RNAs. ${ }^{9,10}$

(2) Artificial RNA aptamers, as high-affinity binders of biomolecules, constitute a large therapeutic class. Endogenous lncRNAs fold into secondary structures, and more so than mRNAs. ${ }^{102}$ Notable are conserved stem-loop structures in protein-interaction interfaces. With a novel in vitro sequence evolution methods in development (e.g., SELEX with Pol $\theta$ CS13 ribonucleotidyl transferases that deliver random RNA libraries and tolerate 2'-functionalized ribonucleotides ${ }^{103}$ ), it becomes tangible to engineer protein- or metabolite-binding RNAs, much like small molecules are classically used as protein-targeting "drugs." An alternative application of RNA aptamers is to bind surface receptors in diseased cells and confer cell entry of drugs and effectors fused to RNA. ${ }^{104}$

(3) Therapeutically relevant peptides can be expressed from designer lncRNA: Although the vast majority of linear and circular IncRNAs are endogenously not translated to polypeptides by ribosomes, there are exceptions: small ORFs encoding micropeptides are known in lncRNAs, and some have cardiovascular relevance (LINC0094 $8 \rightarrow$ myoregulin; SMIM6 $\rightarrow$ endoregulin; LOC100507537 $\rightarrow$ DWORF). ${ }^{105}$ Also, a tiny fraction of native circRNAs can be translated if noncoding RNA segments in the circle fold into internal ribosome entry sites (IRES) to drive translation initiation (circZNF609). ${ }^{26}$ Therefore, one future therapeutic option would be to circularize mRNA to obtain stable expression of therapeutic proteins from a designer circRNA containing an artificial IRES sequence.

(4) Immunotherapy of atherosclerosis by boosting innate immune signaling: One future option for atherosclerosis therapy is to boost specific branches in innate-adaptive immune system cross-talk, a concept stemming from research on antitumor strategies (see Ref. ${ }^{106}$ for overview). This may potentially supplement the more classical antiinflammatory strategies to fight atherosclerosis. ${ }^{107}$ Recent insight shows that also noncoding RNA may have a place in immunotherapy: First, externally provided synthetic noncoding RNA or RNA analogs are already used as adjuvants to increase the immunogenicity of peptide-based vaccination, by virtue of their ability to stimulate cytoplasmic innate immunity receptors RIG-I and MDA5 as "nonself."108-110 Vaccinations, such as with the tolerizing apoB100 epitope, ${ }^{111}$ might in the future benefit. Controlling RIG-I signaling, as far as known from the cancer field, may well also be therapeutically useful for atherosclerosis therapy. The aim here may be to induce programmed cell death by natural killer cells, to enhance phagocytosis by dendritic cell subtypes, to leverage the contribution of specific $\mathrm{T}$ cell subtypes in resolving lesions, and to promote neoantigen presentation to lymphocytes. ${ }^{112}$ A broad MDA-5 and RIG-I activation by RNA is, however, certainly not the goal, because this is known to promote proinflammatory signaling in ECs and macrophages ${ }^{113}$ or osteogenic calcification in aortic VSMCs. ${ }^{114}$ As of yet, too little is known about the cross-talk between innate ${ }^{115}$ and adaptive immunity ${ }^{116}$ in atherosclerosis. Therefore, it is open whether it would be beneficial to transfect synthetic noncoding (uncapped or circular) RNAs as therapeutic triggers of RIG-I 117,118 into specific protective immune cell types, or whether, oppositely, it is the reduction of endogenous RIG-I signaling that may bear protective effects.

\section{Molecular Techniques for IncRNA-Based Therapy}

In the following, we briefly describe different modern technologies to knockdown, overexpress, and study aberrantly 
expressed or spliced lncRNAs or to change their sequence content for the purpose of therapy (-Fig. 2). On a general note, drug development in atherosclerosis often starts out with disease modeling in animals because not all relevant disease-initiating cell-cell interactions can be recapitulated in cell culture models.

\section{Therapeutic Modulation of IncRNA Levels In Vivo}

In the first place, identifying lncRNAs with potential therapeutic relevance necessitates finding animal orthologs of human disease-linked IncRNAs. In atherosclerosis, this can be straightforward (Malat1, Miat, Rncr3, H19), or more complicated (ANRIL ${ }^{119}$ ), because evolutionary selective constraint for the majority of lncRNA sequences is modest at most, and exon-intron structure changes accordingly faster than for protein-coding genes. ${ }^{120}$ If the genomic structure of an atherosclerosis-relevant locus is overall conserved but yields noncoding RNA with only limited conservation, humanizing synthetic disease-linked regions in mice with relevant human IncRNAs through knock-ins may be a viable approach.

If mouse lncRNA orthologs exist, knockdown techniques can be directly executed, involving lncRNA depletion via the RNAi machinery (mostly in the cytoplasm), RNase-H1-type enzymes (also in the cell nucleus), or RNA-cutting ribozymes (-Fig. 2B). Conversely, lncRNA overexpression occurs from plasmids or viral vectors. For circRNA biogenesis from DNA vectors, in many studies, reverse complementary intronic repeats are routinely placed adjacent to circularizing exons, which support backsplicing through backfolding (see Refs. ${ }^{9}$ and ${ }^{10}$ for review). An interesting new concept are selfamplifying RNA “replicons," derived from disarmed, cytoplasmic, self-replicating RNA-alphaviruses, which can make RNA therapy permanent without the need for genome integration of RNA-generating vectors. ${ }^{121}$ Another novel approach employs guide RNAs to target heterologous activator or repressor domains to lncRNA promoters, which causes up-/downregulation of transcription efficiency. ${ }^{122}$

Apart from expression via vectors, IncRNAs can also be locally provided to the target tissue, which is the arterial lesion-containing vessel wall, by transfection of in vitroproduced RNA molecules: One problem of this approach is that routine solid-phase chemical RNA synthesis is still sizelimited (currently $100 \mathrm{nts}$ ). Thus, lncRNAs, due to their size, are often transcribed by T7 RNA polymerase in vitro. Also, RNA circularization is possible in vitro. Thereby, linear T7 transcripts are circularized, either chemically through artificial linkers (e.g., via phosphotriester or click chemistry) or enzymatically through 2 '-5' or 3'-5 backbone linkage (via T4 DNA/RNA ligases, tRNA ligases, or ribozymes such as group II intron derivatives) (see Ref. ${ }^{123}$ for review). Recombinant expression in heterologous hosts (Escherichia coli, yeast) would allow higher linear or circular IncRNAs yield than achieved by in vitro transcription, but so far suffered from stability issues and heterogeneity of RNA ends. Novel unconventional bacterial hosts, such as the marine Rhodovulum sulfidophilum, circumvent some problems, as they secrete nucleic acids but do not contain RNases in their extracellular space. ${ }^{124}$ Together, novel expression hosts, RNA affinity tags, and methods like exponential in vitro synthesis of RNA through polymerase chain transcription ${ }^{125}$ allow producing sufficient amounts of high-quality RNA for therapy (see Ref. 126 for an overview).

\section{Designing IncRNA Function by Modulating RNA Sequence}

In addition to modifying lncRNA levels, a second therapeutic approach is to create designer lncRNAs, whose RNA sequence, structural motifs, or posttranscriptional modifications are purposely engineered. Enabling sequence modifications in vivo, the technical evolution of Cas enzymes has recently made a significant step forward. Instead of modifying DNA via the classical Cas9 enzymes, Cas13 nucleases were found to target RNA. In one application, Cas13 derivatives allow to purposefully destruct RNAs. ${ }^{127,128}$ But Cas13 derivatives also serve to modify RNA sequence when fusing Cas13 to the ADAR2 enzyme: The latter confers adenosine deamination to inosine in a target RNA, with inosine being functionally equivalent to guanosine in translation and splicing (termed REPAIR tool in - Fig. 2B). ${ }^{128}$ Linking other RNAmodifying enzymes to Cas13 has potential to modify target RNAs in different ways.

A range of artificial chemical RNA modifications (both at bases and in the phosphodiester backbone) have been chemically introduced in synthetic therapeutic nucleic acids, and benefits for therapy have been determined, mostly from experience with ASOs. Some modifications improve resistance against nucleases, increase potency, or improve pharmacokinetic properties and cellular uptake (see Ref. ${ }^{129}$ for review). Covalent modifications, as used in ASOs, can theoretically be applied equally to in vitro synthesized lncRNAs, such as links to the ribose 2' position (2'-fluoro, 2'-Omethoxyethyl, or cEt-constrained 2'-O-Ethyl). But to date, chemically modified IncRNAs have not yet been used for therapeutic purposes, in part because any modifications may negatively affect interactions with proteins or client RNAs. On the other hand, insight into the roles of some endogenously occurring posttranscriptional chemical modifications of RNAs (both coding and noncoding) are emerging, paving the field of "epitranscriptomics," as allusion to the so important concept of epigenomic control. For example, methylation $\left(\mathrm{m}^{5} \mathrm{C}, \mathrm{m}^{6} \mathrm{~A}\right)$, pseudouridylation $(\Psi)$, and editing (deamination of A-to-I), known since more than 50 years, have more recently been functionally related to stability (also) of noncoding RNA, ${ }^{130}$ to the formation of higher-order structure necessary for contact with proteins, ${ }^{131,132}$ to splicing, ${ }^{133,134}$ to RNA backbone rigidity ${ }^{135}$ and base-pairing features, ${ }^{136}$ and functional recognition of microRNA binding sites. ${ }^{137,138}$ But this knowledge has not yet been exploited for engineering lncRNA therapy.

\section{Structure-Function Studies in Designer IncRNAs}

In comparison to modulating RNA sequence and covalent modifications on RNA, designing RNA function through engineering secondary and tertiary RNA folds is even more 
complex. Although several native RNAs have evolved to regulate proteins, engineering a protein-activity-regulating IncRNA by bioinformatically designing RNA structure de novo is not yet possible. However, exploring native RNA: protein complexes with new structural methods (e.g. cryoEM), and through chemical probing, now even possibly inside living cells (PARIS, SHAPE-MaP), ${ }^{139}$ will help to control how lncRNAs bind, scaffold, and regulate their molecular targets.

Hand-in-hand goes the development of novel technologies for profiling the molecular detail of lncRNA interactions with chromatin factors in DNA complexes, a major role of IncRNAs. Techniques for this structure-function analysis at a higher level include ChIRP, CHART, RAP, and ChOP (see Ref. 140 for an overview). Insight from these technologies is central because knowing the chromosomal lncRNA targets in disease-relevant cell types is necessary to achieve specificity in lncRNA therapy. ${ }^{127,128}$

\section{Potential Side Effects during Systemic IncRNA Therapy and Therapeutic Implications}

If thoroughly studied, virtually every lncRNA becomes known to engage multiple effector mechanisms in cell type-specific manners. Consequently, side effects are likely in systemic and long-lasting therapy, as applying to atherosclerosis. For example, MALAT1 levels drop in plaques, ${ }^{55}$ and Malat1 knockouts developed atherosclerosis, ${ }^{81}$ suggesting that therapeutic upregulation of MALAT1 might ameliorate disease. On the other hand, MALAT1 is upregulated in cancer cells and is cancer-promoting. ${ }^{84}$ Such dichotomy necessitates tools for conditional lncRNA delivery. Similar disastrous side effects and dangers regarding cancer development and metabolic syndrome apply to circHIPK3 and Gas5.

To avoid these side effects, and also to counteract offtargeting, conditional delivery schemes are necessary: For guiding their expression in atherosclerotic lesions within the vascular wall, synthetic lncRNAs can be conjugated to plaque-homing peptides (e.g., Ac2-26/LyP-1), ${ }^{141}$ antibodies or lipid/lipoprotein carriers (high-density lipoprotein), ${ }^{142}$ or be packaged in lipid vesicles with targeting cues on their surface (e.g., CCR receptors). The most modern relevant approach for conditional expression in biomedicine is localized delivery through photo- and optoacoustic approaches. ${ }^{143}$ An alternative is to elute RNA from coated stents or from perivascular hydrogels. Not last, IncRNA activity can, in principle, be controlled by laser light, when lncRNA are synthesized with optogenetically regulatable backbones or caging groups, ${ }^{144}$ but optogenetic control of IncRNAs has not yet been performed in therapy in vivo, so far.

\section{Conclusion}

To date, around 70 clinical trials are known to center on RNA therapeutics, and these exclusively involve small interfering ASOs/siRNAs and therapeutic mRNAs, but not yet IncRNAs. ${ }^{145}$ Despite the relatively slow translation of RNAcentered therapy into the clinics, ${ }^{145}$ RNA therapeutics is gaining renewed interest, not last through novel insights into lncRNA biology. Further, the ease by which candidate IncRNA can be screened and optimized in their interaction with disease targets surpasses the work with classical small molecule drugs whose targeting to proteins is complex to predict, control, and modify. Any future therapy with lncRNAs will benefit from insight into RNA mass production, chemical modifications, and cellular delivery schemes developed for ASOs/siRNAs over the last decades. As many of the previously unknown cell subtypes that contribute to plaque growth currently become molecularly characterized by novel methods like mass spectrometric cytometry, ${ }^{146-148}$ and as methods for RNA chromatin profiling at single-cell resolution from limited tissue sources emerge, ${ }^{149}$ the vision of a highly specific IncRNA-centered therapy in atherosclerosis is materializing, possibly sooner than expected.

\section{Funding}

This work was in part funded by the German Research Foundation (DFG) as part of the Collaborative Research Center CRC1123 "Atherosclerosis - Mechanisms and Networks of Novel Therapeutic Targets" (project B1) and by the Leducq-foundation CADgenomics.

Conflict of Interest

None declared.

\section{References}

1 Bertone P, Stolc V, Royce TE, et al. Global identification of human transcribed sequences with genome tiling arrays. Science 2004; 306(5705):2242-2246

2 Carninci P, Kasukawa T, Katayama S, et al; FANTOM Consortium; RIKEN Genome Exploration Research Group and Genome Science Group (Genome Network Project Core Group). The transcriptional landscape of the mammalian genome. Science 2005;309(5740):1559-1563

3 Birney E, Stamatoyannopoulos JA, Dutta A, et al; ENCODE Project Consortium; NISC Comparative Sequencing Program; Baylor College of Medicine Human Genome Sequencing Center; Washington University Genome Sequencing Center; Broad Institute; Children's Hospital Oakland Research Institute. Identification and analysis of functional elements in $1 \%$ of the human genome by the ENCODE pilot project. Nature 2007;447 (7146):799-816

4 Djebali S, Davis CA, Merkel A, et al. Landscape of transcription in human cells. Nature 2012;489(7414):101-108

5 Hon CC, Ramilowski JA, Harshbarger J, et al. An atlas of human long non-coding RNAs with accurate 5' ends. Nature 2017;543 (7644):199-204

6 Maurano MT, Humbert R, Rynes E, et al. Systematic localization of common disease-associated variation in regulatory DNA. Science 2012;337(6099):1190-1195

7 Andersson R, Gebhard C, Miguel-Escalada I, et al. An atlas of active enhancers across human cell types and tissues. Nature 2014;507(7493):455-461

8 Ørom UA, Derrien T, Beringer M, et al. Long noncoding RNAs with enhancer-like function in human cells. Cell 2010;143(01):46-58

9 Barrett SP, Salzman J. Circular RNAs: analysis, expression and potential functions. Development 2016;143(11):1838-1847

10 Holdt LM, Kohlmaier A, Teupser D. Molecular roles and function of circular RNAs in eukaryotic cells. Cell Mol Life Sci 2018;75(06): 1071-1098 
11 Engreitz JM, Haines JE, Perez EM, et al. Local regulation of gene expression by IncRNA promoters, transcription and splicing. Nature 2016;539(7629):452-455

12 Lai F, Orom UA, Cesaroni M, et al. Activating RNAs associate with Mediator to enhance chromatin architecture and transcription. Nature 2013;494(7438):497-501

13 Huber F, Bunina D, Gupta I, et al. Protein abundance control by non-coding antisense transcription. Cell Reports 2016;15(12): 2625-2636

14 Yang L, Lin C, Liu W, et al. ncRNA- and Pc2 methylationdependent gene relocation between nuclear structures mediates gene activation programs. Cell 2011;147(04):773-788

15 Yamazaki T, Souquere S, Chujo T, et al. Functional domains of NEAT1 architectural IncRNA induce paraspeckle assembly through phase separation. Mol Cell 2018;70(06):1038-1053

16 Denzler R, McGeary SE, Title AC, Agarwal V, Bartel DP, Stoffel M. Impact of microRNA levels, target-site complementarity, and cooperativity on competing endogenous RNA-regulated gene expression. Mol Cell 2016;64(03):565-579

17 Chu C, Zhang QC, da Rocha ST, et al. Systematic discovery of Xist RNA binding proteins. Cell 2015;161(02):404-416

18 Holdt LM, Stahringer A, Sass K, et al. Circular non-coding RNA ANRIL modulates ribosomal RNA maturation and atherosclerosis in humans. Nat Commun 2016;7:12429

19 Yap KL, Li S, Muñoz-Cabello AM, et al. Molecular interplay of the noncoding RNA ANRIL and methylated histone $\mathrm{H3}$ lysine 27 by polycomb CBX7 in transcriptional silencing of INK4a. Mol Cell 2010;38(05):662-674

20 Holdt LM, Hoffmann S, Sass K, et al. Alu elements in ANRIL noncoding RNA at chromosome 9p21 modulate atherogenic cell functions through trans-regulation of gene networks. PLoS Genet 2013;9(07):e1003588

21 Zhou X, Han X, Wittfeldt A, et al. Long non-coding RNA ANRIL regulates inflammatory responses as a novel component of NFкB pathway. RNA Biol 2016;13(01):98-108

22 Chen R, Kong P, Zhang F, et al. EZH2-mediated $\alpha$-actin methylation needs lncRNA TUG1, and promotes the cortex cytoskeleton formation in VSMCs. Gene 2017;616:52-57

$23 \mathrm{Su}$ IH, Dobenecker MW, Dickinson E, et al. Polycomb group protein ezh2 controls actin polymerization and cell signaling. Cell 2005;121(03):425-436

24 Sharma S, Findlay GM, Bandukwala HS, et al. Dephosphorylation of the nuclear factor of activated T cells (NFAT) transcription factor is regulated by an RNA-protein scaffold complex. Proc Natl Acad Sci U S A 2011;108(28):11381-11386

$25 \mathrm{Li}$, Chen C, Ma X, et al. Long noncoding RNA NRON contributes to HIV-1 latency by specifically inducing tat protein degradation. Nat Commun 2016;7:11730

26 Wesselhoeft RA, Kowalski PS, Anderson DG. Engineering circular RNA for potent and stable translation in eukaryotic cells. Nat Commun 2018;9(01):2629

27 Sampath K, Ephrussi A. CncRNAs: RNAs with both coding and non-coding roles in development. Development 2016;143(08): 1234-1241

28 Lanz RB, McKenna NJ, Onate SA, et al. A steroid receptor coactivator, SRA, functions as an RNA and is present in an SRC1 complex. Cell 1999;97(01):17-27

29 Candeias MM, Malbert-Colas L, Powell DJ, et al. P53 mRNA controls p53 activity by managing Mdm2 functions. Nat Cell Biol 2008;10(09):1098-1105

30 Cheng Z, Otto GM, Powers EN, et al. Pervasive, coordinated protein-level changes driven by transcript isoform switching during meiosis. Cell 2018;172(05):910-923

31 Van Dalfsen KM, Hodapp S, Keskin A, et al. Global proteome remodeling during ER stress involves Hac1-driven expression of long undecoded transcript isoforms. Dev Cell 2018;46(02): 219-235
32 Chia M, Tresenrider A, Chen J, et al. Transcription of a 5' extended mRNA isoform directs dynamic chromatin changes and interference of a downstream promoter. eLife 2017;6:6

33 Shan K, Liu C, Liu BH, et al. Circular noncoding RNA HIPK3 mediates retinal vascular dysfunction in diabetes mellitus. Circulation 2017;136(17):1629-1642

34 Liu C, Yao MD, Li CP, et al. Silencing of circular RNA-ZNF609 ameliorates vascular endothelial dysfunction. Theranostics 2017;7(11):2863-2877

35 Chen L, Yang W, Guo Y, et al. Exosomal lncRNA GAS5 regulates the apoptosis of macrophages and vascular endothelial cells in atherosclerosis. PLoS One 2017;12(09):e0185406

36 Tang R, Zhang G, Wang YC, Mei X, Chen SY. The long non-coding RNA GAS5 regulates transforming growth factor $\beta$ (TGF- $\beta$ )induced smooth muscle cell differentiation via RNA Smadbinding elements. J Biol Chem 2017;292(34):14270-14278

37 Han Y, Ma J, Wang J, Wang L. Silencing of H19 inhibits the adipogenesis and inflammation response in ox-LDL-treated Raw264.7 cells by up-regulating miR-130b. Mol Immunol 2018;93:107-114

38 Li DY, Busch A, Jin H, et al. H19 induces abdominal aortic aneurysm development and progression. Circulation 2018;138 (15):1551-1568

39 Hofmann P, Sommer J, Theodorou K, et al. Long non-coding RNA H19 regulates endothelial cell aging via inhibition of Stat3 signaling. Cardiovasc Res 2019;115(01):230-242

40 Vigetti D, Deleonibus S, Moretto P, et al. Natural antisense transcript for hyaluronan synthase 2 (HAS2-AS1) induces transcription of HAS2 via protein O-GlcNAcylation. J Biol Chem 2014; 289(42):28816-28826

41 van den Boom M, Sarbia M, von Wnuck Lipinski K, et al. Differential regulation of hyaluronic acid synthase isoforms in human saphenous vein smooth muscle cells: possible implications for vein graft stenosis. Circ Res 2006;98(01):36-44

42 Peng Y, Meng K, Jiang L, et al. Thymic stromal lymphopoietininduced HOTAIR activation promotes endothelial cell proliferation and migration in atherosclerosis. Biosci Rep 2017;37(04): BSR20170351

43 Liu J, Huang GQ, Ke ZP. Silence of long intergenic noncoding RNA HOTAIR ameliorates oxidative stress and inflammation response in ox-LDL-treated human macrophages by upregulating miR330-5p. J Cell Physiol 2019;234(04):5134-5142

44 Liao B, Chen R, Lin F, et al. Long noncoding RNA HOTTIP promotes endothelial cell proliferation and migration via activation of the Wnt/ $\beta$-catenin pathway. J Cell Biochem 2018;119(03): 2797-2805

45 Huang C, Hu YW, Zhao JJ, et al. Long noncoding RNA HOXC-AS1 suppresses ox-LDL-induced cholesterol accumulation through promoting HOXC6 expression in THP-1 macrophages. DNA Cell Biol 2016;35(11):722-729

46 Miao Y, Ajami NE, Huang TS, et al. Enhancer-associated long noncoding RNA LEENE regulates endothelial nitric oxide synthase and endothelial function. Nat Commun 2018;9(01):292

47 Rapicavoli NA, Qu K, Zhang J, Mikhail M, Laberge RM, Chang HY. A mammalian pseudogene IncRNA at the interface of inflammation and anti-inflammatory therapeutics. eLife 2013;2:e00762

48 Zhang DD, Wang WT, Xiong J, et al. Long noncoding RNA LINC00305 promotes inflammation by activating the AHRRNF-kB pathway in human monocytes. Sci Rep 2017;7:46204

49 Zhang BY, Jin Z, Zhao Z. Long intergenic noncoding RNA 00305 sponges miR-136 to regulate the hypoxia induced apoptosis of vascular endothelial cells. Biomed Pharmacother 2017;94:238-243

50 Carpenter S, Aiello D, Atianand MK, et al. A long noncoding RNA mediates both activation and repression of immune response genes. Science 2013;341(6147):789-792

$51 \mathrm{Hu} \mathrm{G}$, Gong AY, Wang Y, et al. LincRNA-Cox2 promotes late inflammatory gene transcription in macrophages through 
modulating SWI/SNF-mediated chromatin remodeling J Immunol 2016;196(06):2799-2808

52 Covarrubias S, Robinson EK, Shapleigh B, et al. CRISPR/Cas-based screening of long non-coding RNAs (lncRNAs) in macrophages with an NF-KB reporter.J Biol Chem 2017;292(51):20911-20920

53 Hu YW, Yang JY, Ma X, et al. A lincRNA-DYNLRB2-2/GPR119/GLP$1 \mathrm{R} / \mathrm{ABCA1}$-dependent signal transduction pathway is essential for the regulation of cholesterol homeostasis. J Lipid Res 2014;55 (04):681-697

$54 \mathrm{Wu}$ G, Cai J, Han Y, et al. LincRNA-p21 regulates neointima formation, vascular smooth muscle cell proliferation, apoptosis, and atherosclerosis by enhancing p53 activity. Circulation 2014; 130(17):1452-1465

55 Arslan S, Berkan Ö, Lalem T, et al; Cardiolinc ${ }^{\mathrm{TM}}$ networ. Long noncoding RNAs in the atherosclerotic plaque. Atherosclerosis 2017; 266:176-181

56 Gast M, Rauch BH, Nakagawa S, et al. Immune system-mediated atherosclerosis caused by deficiency of long noncoding RNA MALAT1 in ApoE-/- mice. Cardiovasc Res 2019;115(02): 302-314

57 Lino Cardenas CL, Kessinger CW, Cheng Y, et al. An HDAC9MALAT1-BRG1 complex mediates smooth muscle dysfunction in thoracic aortic aneurysm. Nat Commun 2018;9(01):1009

58 Leisegang MS, Fork C, Josipovic I, et al. Long noncoding RNA MANTIS facilitates endothelial angiogenic function. Circulation 2017;136(01):65-79

$59 \mathrm{Wu}$ Z, He Y, Li D, et al. Long noncoding RNA MEG3 suppressed endothelial cell proliferation and migration through regulating miR-21. Am J Transl Res 2017;9(07):3326-3335

60 Zhou Y, Zhong Y, Wang Y, et al. Activation of p53 by MEG3 noncoding RNA. J Biol Chem 2007;282(34):24731-24742

61 Sallam T, Jones M, Thomas BJ, et al. Transcriptional regulation of macrophage cholesterol efflux and atherogenesis by a long noncoding RNA. Nat Med 2018;24(03):304-312

62 Yan B, Yao J, Liu JY, et al. IncRNA-MIAT regulates microvascular dysfunction by functioning as a competing endogenous RNA. Circ Res 2015;116(07):1143-1156

63 Zhao J, Zhang W, Lin M, et al. MYOSLID is a novel serum response factor-dependent long noncoding RNA that amplifies the vascular smooth muscle differentiation program. Arterioscler Thromb Vasc Biol 2016;36(10):2088-2099

64 Ahmed ASI, Dong K, Liu J, et al. Long noncoding RNA NEAT1 (nuclear paraspeckle assembly transcript 1 ) is critical for phenotypic switching of vascular smooth muscle cells. Proc Natl Acad Sci U S A 2018;115(37):E8660-E8667

65 Sun J, Chen G, Jing Y, et al. LncRNA expression profile of human thoracic aortic dissection by high-throughput sequencing. Cell Physiol Biochem 2018;46(03):1027-1041

66 Krawczyk M, Emerson BM. p50-associated COX-2 extragenic RNA (PACER) activates COX-2 gene expression by occluding repressive NF-KB complexes. eLife 2014;3:e01776

67 Shan K, Jiang Q Wang XQ et al. Role of long non-coding RNARNCR3 in atherosclerosis-related vascular dysfunction. Cell Death Dis 2016;7(06):e2248

68 Shahmoradi N, Nasiri M, Kamfiroozi H, Kheiry MA. Association of the rs555172 polymorphism in SENCR long non-coding RNA and atherosclerotic coronary artery disease. J Cardiovasc Thorac Res 2017;9(03):170-174

69 Boulberdaa M, Scott E, Ballantyne M, et al. A role for the long noncoding RNA SENCR in commitment and function of endothelial cells. Mol Ther 2016;24(05):978-990

70 Ballantyne MD, Pinel K, Dakin R, et al. Smooth muscle enriched long noncoding RNA (SMILR) regulates cell proliferation. Circulation 2016;133(21):2050-2065

71 Man HSJ, Sukumar AN, Lam GC, et al. Angiogenic patterning by STEEL, an endothelial-enriched long noncoding RNA. Proc Natl Acad Sci U S A 2018;115(10):2401-2406
72 Li Z, Chao TC, Chang KY, et al. The long noncoding RNA THRIL regulates TNF $\alpha$ expression through its interaction with hnRNPL. Proc Natl Acad Sci U S A 2014;111(03):1002-1007

73 Zhang L, Cheng H, Yue Y, Li S, Zhang D, He R. TUG1 knockdown ameliorates atherosclerosis via up-regulating the expression of miR-133a target gene FGF1. Cardiovasc Pathol 2018;33:6-15

74 Chen C, Cheng G, Yang X, Li C, Shi R, Zhao N. Tanshinol suppresses endothelial cells apoptosis in mice with atherosclerosis via IncRNA TUG1 up-regulating the expression of miR-26a. Am J Transl Res 2016;8(07):2981-2991

75 Yin D, Fu C, Sun D. Silence of IncRNA UCA1 represses the growth and tube formation of human microvascular endothelial cells through miR-195. Cell Physiol Biochem 2018;49(04):1499-1511

76 Guo J, Cai H, Zheng J, et al. Long non-coding RNA NEAT1 regulates permeability of the blood-tumor barrier via miR-181d-5pmediated expression changes in ZO-1, occludin, and claudin-5. Biochim Biophys Acta Mol Basis Dis 2017;1863(09):2240-2254

77 Ackers-Johnson M, Talasila A, Sage AP, et al. Myocardin regulates vascular smooth muscle cell inflammatory activation and disease. Arterioscler Thromb Vasc Biol 2015;35(04):817-828

78 Chen DD, Hui LL, Zhang XC, Chang Q. NEAT1 contributes to oxLDL-induced inflammation and oxidative stress in macrophages through inhibiting miR-128. J Cell Biochem 2018. Doi: 10.1002/ jcb. 27541

79 Bennett MR, Sinha S, Owens GK. Vascular smooth muscle cells in atherosclerosis. Circ Res 2016;118(04):692-702

80 Yu CK, Xu T, Assoian RK, Rader DJ. Mining the stiffness-sensitive transcriptome in human vascular smooth muscle cells identifies long noncoding RNA stiffness regulators. Arterioscler Thromb Vasc Biol 2018;38(01):164-173

81 Gast M, Schroen B, Voigt A, et al. Long noncoding RNA MALAT1derived mascRNA is involved in cardiovascular innate immunity. J Mol Cell Biol 2016;8(02):178-181

82 Zhang X, Tang X, Liu K, Hamblin MH, Yin KJ. Long noncoding RNA Malat1 regulates cerebrovascular pathologies in ischemic stroke. J Neurosci 2017;37(07):1797-1806

83 Xin JW, Jiang YG. Long noncoding RNA MALAT1 inhibits apoptosis induced by oxygen-glucose deprivation and reoxygenation in human brain microvascular endothelial cells. Exp Ther Med 2017;13(04):1225-1234

84 Arun G, Diermeier S, Akerman M, et al. Differentiation of mammary tumors and reduction in metastasis upon Malat1 lncRNA loss. Genes Dev 2016;30(01):34-51

85 Michalik KM, You X, Manavski Y, et al. Long noncoding RNA MALAT1 regulates endothelial cell function and vessel growth. Circ Res 2014;114(09):1389-1397

86 Hauser AT, Robaa D, Jung M. Epigenetic small molecule modulators of histone and DNA methylation. Curr Opin Chem Biol 2018;45:73-85

87 Gilbert LA, Larson MH, Morsut L, et al. CRISPR-mediated modular RNA-guided regulation of transcription in eukaryotes. Cell 2013; 154(02):442-451

88 Qi LS, Larson MH, Gilbert LA, et al. Repurposing CRISPR as an RNA-guided platform for sequence-specific control of gene expression. Cell 2013;152(05):1173-1183

89 Ashwal-Fluss R, Meyer M, Pamudurti NR, et al. circRNA biogenesis competes with pre-mRNA splicing. Mol Cell 2014;56(01): $55-66$

90 Zhang Y, Xue W, Li X, et al. The biogenesis of nascent circular RNAs. Cell Reports 2016;15(03):611-624

91 Zhang XO, Wang HB, Zhang Y, Lu X, Chen LL, Yang L. Complementary sequence-mediated exon circularization. Cell 2014;159 (01):134-147

92 Burd CE, Jeck WR, Liu Y, Sanoff HK, Wang Z, Sharpless NE. Expression of linear and novel circular forms of an INK4/ARFassociated non-coding RNA correlates with atherosclerosis risk. PLoS Genet 2010;6(12):e1001233 
93 Almontashiri NA, Antoine D, Zhou X, et al. 9p21.3 coronary artery disease risk variants disrupt TEAD transcription factordependent transforming growth factor $\beta$ regulation of $\mathrm{p} 16$ expression in human aortic smooth muscle cells. Circulation 2015;132(21):1969-1978

94 Miller CL, Pjanic M, Wang T, et al. Integrative functional genomics identifies regulatory mechanisms at coronary artery disease loci. Nat Commun 2016;7:12092

95 Mumbach MR, Satpathy AT, Boyle EA, et al. Enhancer connectome in primary human cells identifies target genes of diseaseassociated DNA elements. Nat Genet 2017;49(11):1602-1612

96 Scotti MM, Swanson MS. RNA mis-splicing in disease. Nat Rev Genet 2016;17(01):19-32

97 Goettsch C, Rauner M, Hamann C, et al. Nuclear factor of activated $\mathrm{T}$ cells mediates oxidised LDL-induced calcification of vascular smooth muscle cells. Diabetologia 2011;54(10): 2690-2701

98 von Lukowicz T, Hassa PO, Lohmann C, et al. PARP1 is required for adhesion molecule expression in atherogenesis. Cardiovasc Res 2008;78(01):158-166

99 Chen YG, Satpathy AT, Chang HY. Gene regulation in the immune system by long noncoding RNAs. Nat Immunol 2017;18(09): 962-972

100 Tabas I, Lichtman AH. Monocyte-macrophages and T cells in atherosclerosis. Immunity 2017;47(04):621-634

101 Jost I, Shalamova LA, Gerresheim GK, Niepmann M, Bindereif A, Rossbach O. Functional sequestration of microRNA-122 from Hepatitis C Virus by circular RNA sponges. RNA Biol 2018;15 (08):1032-1039

102 Spitale RC, Flynn RA, Zhang QC, et al. Structural imprints in vivo decode RNA regulatory mechanisms. Nature 2015;519 (7544):486-490

103 Randrianjatovo-Gbalou I, Rosario S, Sismeiro O, et al. Enzymatic synthesis of random sequences of RNA and RNA analogues by DNA polymerase theta mutants for the generation of aptamer libraries. Nucleic Acids Res 2018;46(12):6271-6284

104 Pastor F, Kolonias D, Giangrande PH, Gilboa E. Induction of tumour immunity by targeted inhibition of nonsense-mediated mRNA decay. Nature 2010;465(7295):227-230

105 Nelson BR, Makarewich CA, Anderson DM, et al. A peptide encoded by a transcript annotated as long noncoding RNA enhances SERCA activity in muscle. Science 2016;351 (6270):271-275

106 Gajewski TF, Schreiber H, Fu YX. Innate and adaptive immune cells in the tumor microenvironment. Nat Immunol 2013;14 (10):1014-1022

107 Bäck M, Hansson GK. Anti-inflammatory therapies for atherosclerosis. Nat Rev Cardiol 2015;12(04):199-211

108 Chen YG, Kim MV, Chen X, et al. Sensing self and foreign circular RNAs by Intron identity. Mol Cell 2017;67(02):228-238

109 Coffman RL, Sher A, Seder RA. Vaccine adjuvants: putting innate immunity to work. Immunity 2010;33(04):492-503

110 Wang L, Smith D, Bot S, Dellamary L, Bloom A, Bot A. Noncoding RNA danger motifs bridge innate and adaptive immunity and are potent adjuvants for vaccination. J Clin Invest 2002;110(08): 1175-1184

111 Kimura T, Tse K, McArdle S, et al. Atheroprotective vaccination with MHC-II-restricted ApoB peptides induces peritoneal IL-10producing CD4 T cells. Am J Physiol Heart Circ Physiol 2017;312 (04):H781-H790

112 Elion DL, Cook RS. Harnessing RIG-I and intrinsic immunity in the tumor microenvironment for therapeutic cancer treatment. Oncotarget 2018;9(48):29007-29017

113 Asdonk T, Steinmetz M, Krogmann A, et al. MDA-5 activation by cytoplasmic double-stranded RNA impairs endothelial function and aggravates atherosclerosis. J Cell Mol Med 2016;20(09): 1696-1705
114 Ramachandran B, Stabley JN, Cheng SL, et al. A GTPase-activating protein-binding protein (G3BP1)/antiviral protein relay conveys arteriosclerotic Wnt signals in aortic smooth muscle cells. J Biol Chem 2018;293(21):7942-7968

115 Christ A, Bekkering S, Latz E, Riksen NP. Long-term activation of the innate immune system in atherosclerosis. Semin Immunol 2016;28(04):384-393

116 Wolf D, Ley K. Immunity and inflammation in atherosclerosis. Circ Res 2019;124(02):315-327

117 Li X, Liu CX, Xue W, et al. Coordinated circRNA biogenesis and function with NF90/NF110 in viral infection. Mol Cell 2017;67 (02):214-227

118 Hochheiser K, Klein M, Gottschalk C, et al. Cutting edge: the RIG-I ligand 3pRNA potently improves CTL cross-priming and facilitates antiviral vaccination. J Immunol 2016;196(06):2439-2443

119 Visel A, Zhu Y, May D, et al. Targeted deletion of the 9p21 noncoding coronary artery disease risk interval in mice. Nature 2010;464(7287):409-412

120 Ulitsky I. Evolution to the rescue: using comparative genomics to understand long non-coding RNAs. Nat Rev Genet 2016;17(10): 601-614

121 Kim DY, Atasheva S, McAuley AJ, et al. Enhancement of protein expression by alphavirus replicons by designing self-replicating subgenomic RNAs. Proc Natl Acad Sci U S A 2014;111(29): 10708-10713

122 Bester AC, Lee JD, Chavez A, et al. An integrated genome-wide CRISPRa approach to functionalize lncRNAs in drug resistance. Cell 2018;173(03):649-664

123 Müller S, Appel B. In vitro circularization of RNA. RNA Biol 2017; 14(08):1018-1027

124 Suzuki H, Ando T, Umekage S, Tanaka T, Kikuchi Y. Extracellular production of an RNA aptamer by ribonuclease-free marine bacteria harboring engineered plasmids: a proposal for industrial RNA drug production. Appl Environ Microbiol 2010;76(03): 786-793

125 Chen T, Romesberg FE. Polymerase chain transcription: exponential synthesis of RNA and modified RNA. J Am Chem Soc 2017;139(29):9949-9954

126 Baronti L, Karlsson H, Marušič M, Petzold K. A guide to large-scale RNA sample preparation. Anal Bioanal Chem 2018;410(14): 3239-3252

127 Abudayyeh OO, Gootenberg JS, Essletzbichler P, et al. RNA targeting with CRISPR-Cas13. Nature 2017;550(7675):280-284

128 Cox DBT, Gootenberg JS, Abudayyeh OO, et al. RNA editing with CRISPR-Cas13. Science 2017;358(6366):1019-1027

129 Khvorova A, Watts JK. The chemical evolution of oligonucleotide therapies of clinical utility. Nat Biotechnol 2017;35(03):238-248

130 Wang Y, Li Y, Toth JI, Petroski MD, Zhang Z, Zhao JC. N6-methyladenosine modification destabilizes developmental regulators in embryonic stem cells. Nat Cell Biol 2014;16(02):191-198

131 Liu N, Dai Q, Zheng G, He C, Parisien M, Pan T. N(6)-methyladenosine-dependent RNA structural switches regulate RNA-protein interactions. Nature 2015;518(7540):560-564

132 Patil DP, Chen CK, Pickering BF, et al. m(6)A RNA methylation promotes XIST-mediated transcriptional repression. Nature 2016;537(7620):369-373

133 Kasowitz SD, Ma J, Anderson SJ, et al. Nuclear m6A reader YTHDC1 regulates alternative polyadenylation and splicing during mouse oocyte development. PLoS Genet 2018;14(05): e1007412

134 Rueter SM, Dawson TR, Emeson RB. Regulation of alternative splicing by RNA editing. Nature 1999;399(6731):75-80

135 Davis DR. Stabilization of RNA stacking by pseudouridine. Nucleic Acids Res 1995;23(24):5020-5026

136 Karijolich J, Yu YT. Converting nonsense codons into sense codons by targeted pseudouridylation. Nature 2011;474 (7351):395-398 
137 Kawahara Y, Zinshteyn B, Sethupathy P, lizasa H, Hatzigeorgiou AG, Nishikura K. Redirection of silencing targets by adenosine-toinosine editing of miRNAs. Science 2007;315(5815):1137-1140

138 Goldstein B, Agranat-Tamir L, Light D, Ben-Naim Zgayer O, Fishman A, Lamm AT. A-to-I RNA editing promotes developmental stage-specific gene and lncRNA expression. Genome Res 2017; 27(03):462-470

139 Smola MJ, Weeks KM. In-cell RNA structure probing with SHAPEMaP. Nat Protoc 2018;13(06):1181-1195

140 Kashi K, Henderson L, Bonetti A, Carninci P. Discovery and functional analysis of lncRNAs: methodologies to investigate an uncharacterized transcriptome. Biochim Biophys Acta 2016; 1859(01):3-15

141 Kamaly N, Fredman G, Subramanian M, et al. Development and in vivo efficacy of targeted polymeric inflammation-resolving nanoparticles. Proc Natl Acad Sci U S A 2013;110(16):6506-6511

142 Duivenvoorden R, Tang J, Cormode DP, et al. A statin-loaded reconstituted high-density lipoprotein nanoparticle inhibits atherosclerotic plaque inflammation. Nat Commun 2014; 5:3065
143 Zhang Y, Yu J, Kahkoska AR, Gu Z. Photoacoustic drug delivery. Sensors (Basel) 2017;17(06):E1400

144 Lubbe AS, Szymanski W, Feringa BL. Recent developments in reversible photoregulation of oligonucleotide structure and function. Chem Soc Rev 2017;46(04):1052-1079

145 Kaczmarek JC, Kowalski PS, Anderson DG. Advances in the delivery of RNA therapeutics: from concept to clinical reality. Genome Med 2017;9(01):60

146 Cole JE, Park I, Ahern DJ, et al. Immune cell census in murine atherosclerosis: cytometry by time of flight illuminates vascular myeloid cell diversity. Cardiovasc Res 2018;114(10):1360-1371

147 Misra A, Feng Z, Chandran RR, et al. Integrin beta3 regulates clonality and fate of smooth muscle-derived atherosclerotic plaque cells. Nat Commun 2018;9(01):2073

148 Guimarães-Camboa N, Evans SM. Are perivascular adipocyte progenitors mural cells or adventitial fibroblasts? Cell Stem Cell 2017;20(05):587-589

149 Cusanovich DA, Hill AJ, Aghamirzaie D, et al. A single-cell atlas of in vivo mammalian chromatin accessibility. Cell 2018;174(05): $1309-1324$ 